\title{
The influence of temperature on the synthesis of molecules on icy grain mantles in dense molecular clouds
}

\author{
M. Garozzo ${ }^{1}$, L. La Rosa ${ }^{1}$, Z. Kanuchova ${ }^{1,2}$, S. Ioppolo ${ }^{3}$, G. A. Baratta ${ }^{1}$, \\ M. E. Palumbo ${ }^{1}$, and G. Strazzulla ${ }^{1}$ \\ 1 INAF - Osservatorio Astrofisico di Catania, via S. Sofia 78, 95123 Catania, Italy \\ e-mail: [mga; mepalumbo] @oact.inaf.it \\ 2 Astronomical Institute of Slovak Academy of Science, 05960 Tatranska Lomnica, Slovakia \\ 3 Raymond \& Beverly Sackler Laboratory for Astrophysics, Leiden Observatory, Leiden University, PO Box 9513, 2300 RA Leiden, \\ The Netherlands
}

Received 6 July 2010 / Accepted 2 February 2011

\begin{abstract}
Context. Infrared observations show the presence of icy mantles along the line of sight toward young stellar objects (YSOs), where a temperature gradient is expected and indirectly observed. In this environment, icy mantles are affected by ion and UV irradiation. Laboratory experiments show that molecules are formed after irradiation of icy mixtures. However, most of the experiments done so far have been performed in the temperatures range of 10-20 K.

Aims. To extend previous work we irradiated some icy mixtures, namely $\mathrm{H}_{2} \mathrm{O}: \mathrm{CO}=10: 1, \mathrm{H}_{2} \mathrm{O}: \mathrm{CH}_{4}=4: 1$, and $\mathrm{H}_{2} \mathrm{O}: \mathrm{CO}_{2}=3: 1$ at two different temperatures $(12 \mathrm{~K}$ and 40 or $60 \mathrm{~K}$ ) to study the effects of temperature on the synthesis of molecules and the decrease in their parent species after ion irradiation.

Methods. The experiments were performed in a high-vacuum chamber $\left(P<10^{-7} \mathrm{mbar}\right)$, where icy samples were irradiated with $30 \mathrm{keV} \mathrm{He}{ }^{+}$ions and analyzed by a FTIR spectrophotometer. Infrared spectra of the samples were recorded after various steps of irradiation.

Results. We found that the temperature affects the behavior of the volatile species (i.e., $\mathrm{CO}$ and $\mathrm{CH}_{4}$ ) during irradiation. As a consequence, the production of molecular species is generally more prevalent at $12 \mathrm{~K}$ than at either 40 or $60 \mathrm{~K}$, while the decrease in their parent volatile species is faster at high temperature.

Conclusions. We conclude that the behavior of each species depends on the value of its sublimation temperature with respect to the temperature of the sample. If this latter is higher than the sublimation temperature of a given species, then the effects of thermal desorption compete with those due to irradiation.
\end{abstract}

Key words. astrochemistry - molecular processes - methods: laboratory - techniques: spectroscopic - ISM: abundances ISM: molecules

\section{Introduction}

The nearly empty space between the stars is generally referred to as the interstellar medium (ISM). The ISM consists, 99\% in mass, of gas (mainly hydrogen, $\mathrm{H}$ ) and, $1 \%$ in mass, of dust formed by carbonaceous or silicate material as well as polycyclic aromatic hydrocarbons. The ISM is not a uniform environment in neither composition, temperature, nor density. There are locations known as dense molecular clouds (DMCs), where the density of material is relatively high $\left(>10^{4} n_{\mathrm{H}} \mathrm{cm}^{-3}\right)$, thus the clouds are optically thick and the temperature can drop as low as $10 \mathrm{~K}$.

Owing to the high density and low temperature of DMCs, gas phase species adhere to the grain surface accreting an ice coating. Atomic hydrogen can thermally move over the ice matrix and eventually react with other atoms or molecules forming simple molecules, primarily water, which is the most abundant species detected, but also methanol $\left(\mathrm{CH}_{3} \mathrm{OH}\right)$, ammonia $\left(\mathrm{NH}_{3}\right)$, and methane $\left(\mathrm{CH}_{4}\right)$ (e.g., Hiraoka et al. 1998; Watanabe \& Kouchi 2002; Ioppolo et al. 2008; Fuchs et al. 2009; Dulieu et al. 2010). Simultaneously, cosmic ion irradiation produce highenergy processes in the icy mantles, which are deeply chemically and structurally modified. Incoming ions, in fact, release their energy into the target and destroy molecular bonds producing fragments that, by recombination, can form molecules that differ from the original ones and, in general, a modified lattice structure (e.g., Palumbo \& Strazzulla 1993; Palumbo et al. 2004; Garozzo et al. 2010). Moreover, DMCs are found in star-forming regions. Close to a forming protostar, high-energy processes in the icy mantles are also induced by the stellar winds and UV photons originating from the protostar itself. During the evolution of a protostar, the temperature of the environment gradually increases, leading to the sublimation of the more volatile species, which enrich the surrounding gas.

Observations of species in the condensed phase provide insight into the chemical and physical processes in these regions. Therefore, the investigation of the relation between the composition and structure of icy mantles and the physical environment is instrumental in understanding the chemical evolution in the envelopes of young stars. Some of the most abundant molecular species detected in the interstellar medium in solid phase, besides $\mathrm{H}_{2} \mathrm{O}$, are $\mathrm{CO}$ (which directly condenses from the gas phase), $\mathrm{CH}_{3} \mathrm{OH}, \mathrm{CH}_{4}$, carbonyl sulfide (OCS) and carbon dioxide $\left(\mathrm{CO}_{2}\right)$ (e.g., Gibb et al. 2004).

An uncertainty about the chemistry of the ISM concerns the origin of solid $\mathrm{CO}_{2}$ in the icy mantles on the dust particles. IR 
observations of several interstellar clouds show that the abundance of solid $\mathrm{CO}_{2}$, in polar (water-rich) icy mantles, is in the range 10-25\% with respect to water ice, although some sources, e.g., AFGL 989 and Elias 18, exhibit an even higher (34-37\%) $\mathrm{CO}_{2}$ abundance, while $\mathrm{CO}_{2}$ column density in apolar mantles varies strongly, depending critically on the temperature profile along the line of sight (e.g., Gerakines et al. 1999; Gibb et al. 2004; Boogert et al. 2004; Whittet et al. 2007; Pontoppidan et al. 2008).

Different mechanisms have been proposed for the formation of $\mathrm{CO}_{2}$ in icy grain mantles. Owing to the low abundance of this molecule in the gas phase (van Dishoeck et al. 1996; Boonman et al. 2003), it is generally accepted that $\mathrm{CO}_{2}$ is formed on the grain surface via chemical reactions or energetic processing (e.g., Tielens \& Hagen 1982; Palumbo \& Strazzulla 1993; Stantcheva \& Herbst 2004; Fraser \& van Dishoeck 2004).

Ruffle \& Herbst (2001a) published models of coupled gasphase and grain surface chemistry that are appropriate for quiescent dense cores. In their models, these authors investigated the effects of grain mantle photodissociation by considering as photon sources the background interstellar and cosmic-ray-induced radiation fields. Relevant photons are those with energy in the 6.9-13.6 eV range (e.g. Jenniskens et al. 1993). These models based on a fixed set of physical conditions, such as a gas and dust temperature of $10 \mathrm{~K}$, reproduce the abundances of solid $\mathrm{H}_{2} \mathrm{O}$ and $\mathrm{CO}$ observed towards the field star Elias16, but underestimate the abundance of solid $\mathrm{CO}_{2}$, finding a maximum of $1 \%$ with respect to water ice, while the observed abundance is around 23\% (Nummelin et al. 2001). Ruffle \& Herbst (2001b) developed more complete gas-grain models with a variety of densities and temperatures to determine whether a change in these parameters could enhance the production of $\mathrm{CO}_{2}$, while preserving the agreement between the predicted and observed abundance of the other major ice components. They found that, in general, an increase in temperature leads to a significant increase in surface $\mathrm{CO}_{2}$ production because the diffusion rates of the reactants that produce $\mathrm{CO}_{2}$ become much higher, and competitive reactions involving $\mathrm{H}$ atoms become less important as $\mathrm{H}$ desorbs more quickly. However, the fraction of $\mathrm{CO}_{2}$ produced in their models depends strongly also on the physical and chemical conditions adopted, so the results they obtain do not always match the observed $\mathrm{CO}_{2}$ abundance.

Energetic processing, such as UV $(6.9 \leq E \leq 13.6 \mathrm{eV})$ and ion irradiation $(E \sim \mathrm{MeV})$, of icy mantles containing $\mathrm{C}$ - and O-bearing species is another possible mechanism of $\mathrm{CO}_{2}$ production. Laboratory experiments show that $\mathrm{CO}_{2}$ is formed after the irradiation of pure $\mathrm{CO}$ and $\mathrm{H}_{2} \mathrm{O}: \mathrm{CO}$ ice mixtures (e.g., d'Hendecourt et al. 1986; Moore et al. 1991; Gerakines et al. 1996; Ehrenfreund et al. 1997; Palumbo et al. 1998; Loeffler et al. 2005). Furthermore Mennella et al. (2004, 2006), studied the formation of $\mathrm{CO}_{2}$ after the irradiation of $\mathrm{H}_{2} \mathrm{O}$ on $\mathrm{C}$ grains, and Ioppolo et al. (2009) studied the formation of $\mathrm{CO}_{2}$ after ion irradiation of ice mixtures illustrating that the amount of $\mathrm{CO}_{2}$ formed can account for the observed $\mathrm{CO}_{2}$ in YSOs and that laboratory spectra are good spectroscopic analogues of the interstellar features. Another possible source of $\mathrm{C}$ atoms, apart from $\mathrm{CO}$, for accumulating $\mathrm{CO}_{2}$ in the icy grain mantles can be $\mathrm{CH}_{4}$, detected via its feature at $7.67 \mu \mathrm{m}$ in several sources with an abundance in the range $0.3-4 \%$ with respect to water ice (Boogert et al. 1997). Irradiation of $\mathrm{H}_{2} \mathrm{O}: \mathrm{CH}_{4}$ mixtures, in fact, easily produce $\mathrm{CO}_{2}$ (Palumbo et al. 1998).

However, most of the experiments have been performed at low temperature $(10-20 \mathrm{~K})$ to mimic the effects of energetic processing in quiescent regions. On the other hand, icy mantles
Table 1. Details of experiments performed and discussed in this work and investigated dose ranges.

\begin{tabular}{lcc}
\hline \hline Sample & $\begin{array}{c}T \\
(\mathrm{~K})\end{array}$ & $\begin{array}{c}\text { Dose range } \\
(\mathrm{eV} / 16 \mathrm{u})\end{array}$ \\
\hline $\mathrm{H}_{2} \mathrm{O}: \mathrm{CO}=10: 1$ & 12 & $0.7-53$ \\
$\mathrm{H}_{2} \mathrm{O}: \mathrm{CO}=10: 1$ & 40 & $0.7-30$ \\
$\mathrm{H}_{2} \mathrm{O}: \mathrm{CH}_{4}=4: 1$ & 12 & $0.9-185$ \\
$\mathrm{H}_{2} \mathrm{O}: \mathrm{CH}_{4}=4: 1$ & 40 & $1.4-140$ \\
$\mathrm{H}_{2} \mathrm{O}: \mathrm{CO}_{2}=3: 1$ & 12 & $0.6-49$ \\
$\mathrm{H}_{2} \mathrm{O}: \mathrm{CO}_{2}=3: 1$ & 60 & $0.6-48$ \\
\hline
\end{tabular}

Notes. All targets have been irradiated with $30 \mathrm{keV} \mathrm{He}^{+}$ions.

around YSOs are expected to be warmer than $20 \mathrm{~K}$ because of the temperature gradient induced by the protostellar object. The presence of the temperature gradient can be inferred from the profile of the $3 \mu \mathrm{m} \mathrm{H}_{2} \mathrm{O}$ band (e.g., Dartois \& d'Hendecourt 2001) and the profile of the $\mathrm{CO}_{2}$ bands (e.g., Gerakines et al. 1999; Ioppolo et al. 2009). Thus, to extend the experimental work presented by Ioppolo et al. (2009) and investigate the possibility that ion irradiation of warm ices increases the $\mathrm{CO}_{2}$ formation rate as suggested by Ruffle \& Herbst (2001b) in the case of photochemistry, we performed new experiments to study the formation of $\mathrm{CO}_{2}$ (as well as $\mathrm{CO}$ ) and the decrease of the abundance of the original species after ion irradiation of ice mixtures at higher temperatures (40-60 K). These temperatures are higher than the sublimation temperature of pure $\mathrm{CO}$ and $\mathrm{CH}_{4}$ but these molecules remain on the target because they are embedded in the water ice matrix. The results are compared with those obtained after irradiation of the same mixtures at low temperature $(12 \mathrm{~K})$. Details of all the experiments performed and discussed in this work are listed in Table 1.

\section{Experimental apparatus and procedures}

The experiments were performed in a high-vacuum chamber $\left(P<10^{-7}\right.$ mbar) facing, through $\mathrm{KBr}$ windows, a FTIR spectrophotometer (Bruker Equinox 55) working in the spectral range $7500-400 \mathrm{~cm}^{-1}(1.33-25 \mu \mathrm{m})$. Pre-prepared gas mixtures were admitted from a mixing-chamber to the main chamber by a needle valve and accreted in the form of ices on a silicon substrate placed in thermal contact with the tail section of a closed-cycle helium cryostat, whose temperature can vary from 10 to $300 \mathrm{~K}$. Ions were obtained from a $200 \mathrm{kV}$ ion implanter (Danfysik 1080), which is interfaced to the vacuum chamber. The ion beam current densities were maintained below $1 \mu \mathrm{A} \mathrm{cm}^{-2}$ to avoid macroscopic heating of the target. The substrate plane forms an angle of $45^{\circ}$ with the IR beam of the spectrometer and the ion beam (the two being mutually perpendicular), so transmittance spectra can be easily obtained in situ, without tilting the sample. After deposition and each step of irradiation, two IR spectra were recorded, selecting the component of the electric vector parallel ( $P$ polarization) and perpendicular ( $S$ polarization) to the plane of incidence. The polarization was selected using a polarizer placed in the path of the infrared beam in front of the detector. Baratta et al. (2000) and Palumbo et al. (2006) found that when the band profiles recorded in $P$ and $S$ polarization are similar, the features seen in the transmittance spectra directly reflect the variation in the absorption coefficient of the solid sample. This is the case for all the new bands present in our spectra after ion irradiation. Therefore, $P$ spectra were considered in this work since the signal-to-noise ratio is higher for this polarization. However, in the $\mathrm{H}_{2} \mathrm{O}: \mathrm{CO}_{2}$ samples the profile 
Table 2. List of the adopted band strength $(A)$ values.

\begin{tabular}{lccc}
\hline \hline Molecule & $\begin{array}{c}\text { Band } \\
\left(\mathrm{cm}^{-1}\right)\end{array}$ & $\begin{array}{c}A \\
\left.(\mathrm{~cm} \mathrm{molecule})^{-1}\right)\end{array}$ & Reference \\
\hline $\mathrm{H}_{2} \mathrm{O}$ & 3300 & $2.0 \times 10^{-16}$ & Allamandola et al. (1988) \\
$\mathrm{CO}_{2}$ & 2345 & $7.6 \times 10^{-17}$ & Yamada \& Person (1964) \\
$\mathrm{CO}$ & 2139 & $1.1 \times 10^{-17}$ & Jiang et al. (1975) \\
$\mathrm{CH}_{4}$ & 1303 & $6.4 \times 10^{-18}$ & Mulas et al. (1998) \\
\hline
\end{tabular}

of the $\mathrm{CO}_{2}$ band at $2344 \mathrm{~cm}^{-1}$ in $P$ and $S$ polarization is different, because $P$ spectra show both the longitudinal optical mode (LO) and the transverse optical mode (TO), which lead to LOTO splitting (Baratta \& Palumbo 1998; Palumbo et al. 2006). In these samples, the $\mathrm{H}_{2} \mathrm{O}$ band at $3280 \mathrm{~cm}^{-1}$ also has a different profile in $P$ and $S$ spectra. In these mixtures, the area of $\mathrm{CO}_{2}$ and $\mathrm{H}_{2} \mathrm{O}$ bands were calculated from $S$ spectra, which display only evidence of the TO mode, because the intensity of the LO mode does not scale linearly with the column density. The profile of the $\mathrm{CO}$ band produced after ion irradiation in spectra taken by selecting the $P$ and $S$ components are very similar to each other, therefore, the band area was calculated from $P$ spectra because the signal-to-noise ratio is higher for this case. All spectra shown in the following sections are taken by selecting the $P$ component with a resolution of $1 \mathrm{~cm}^{-1}$.

By measuring the ion fluence (ions $\mathrm{cm}^{-2}$ ) and using the SRIM software (Ziegler et al. 2008) to calculate stopping powers, we determined, for each experiment, the radiation doses suffered by the target, on a scale of eV per $16 \mathrm{u}$ molecule, where $\mathrm{u}$ is the unified atomic mass unit, defined as $1 / 12$ of the mass of an isolated atom of carbon-12.

Satorre et al. (2000) and Ioppolo et al. (2009) demonstrated that the relative abundance of molecules formed after ion irradiation depends on the relative abundance of species present in the initial mixture. Thus, a major concern in the work we present here was to obtain the same mixture at different temperatures. We measured the relative abundance of species in the mixtures after deposition from the integrated intensity of the absorption bands using the band strength values reported in Table 2. As said before, to prepare a sample a pre-prepared gas mixture is admitted into the chamber and the sample is accreted onto the cold substrate in the solid phase. Once all the other parameters are fixed, the deposition rate of each species depends only on the temperature of the substrate. Therefore, if the same gas mixture were prepared in the mixing chamber, the ice mixture obtained would depend on the temperature of the substrate (e.g., Quirico $\&$ Schmitt 1997). To obtain ice mixtures with the same relative abundances even at different temperatures, the samples $\mathrm{H}_{2} \mathrm{O}: \mathrm{CO}$ and $\mathrm{H}_{2} \mathrm{O}: \mathrm{CO}_{2}$ irradiated at $12 \mathrm{~K}$ are prepared by depositing the gas mixtures at 40 and $60 \mathrm{~K}$, respectively, and then cooled to $12 \mathrm{~K}$. In the case of the $\mathrm{H}_{2} \mathrm{O}: \mathrm{CH}_{4}$ mixtures, since the accretion rate was calibrated at different temperatures, the samples at 40 and $12 \mathrm{~K}$ were prepared by setting gas mixtures with different relative abundances into the mixing-chamber. The thickness of all the samples is of the order of $0.1 \mu \mathrm{m}$, which is smaller than the penetration depth of the used ions $\left(30 \mathrm{keV} \mathrm{He}^{+}\right)$. Therefore, after the energy is released into the material, the He ions are implanted into the silicon substrate on which ices are deposited. For more details of the experimental setup, the reader is referred to Strazzulla et al. (2001).

In all the graphs shown in this paper, we plot the normalized column density of molecular species, which is inferred from the ratio $N / N_{\mathrm{i}}$ where $N$ is the column density (molecules $\mathrm{cm}^{-2}$ ) of a given species at some point of the irradiation experiment and $N_{\mathrm{i}}$ is the initial column density of the parent molecule. The column density was calculated using the equation:

$N=\frac{\int \tau_{\nu} \mathrm{d} v}{A}$,

where $\int \tau_{\nu} \mathrm{d} v\left(\mathrm{~cm}^{-1}\right)$ is the band area (in an optical depth scale) obtained after subtraction of underlying continuum and $A$ is the band strength $\left(\mathrm{cm}\right.$ molecule $\left.{ }^{-1}\right)$. The $A$-values used in this work are listed in Table 2 . The column density is corrected by a factor of

$\cos \theta_{\mathrm{r}}=\sqrt{1-\frac{\sin ^{2} \theta_{\mathrm{i}}}{n_{\mathrm{f}}^{2}}}$,

where $\theta_{\mathrm{r}}$ is the refractive angle and $n_{\mathrm{f}}$ is the refractive index of the film. This correction takes into account the longer path length of the IR beam at an incidence angle $\theta_{\mathrm{i}}=45 \mathrm{deg}$ (Fulvio et al. 2009; Modica \& Palumbo 2010).

Column density values after irradiation are normalized to the initial column density values to compare the results relative to ice samples with slightly different initial thickness.

The experimental data are fitted by using different exponential curves. The decrease in the column density of the species present in the original mixture is described by the exponential curve

$y=y_{\infty}+\left(Y_{0}-y_{\infty}\right) \mathrm{e}^{-\sigma D}$,

where $y$ is the $N / N_{\mathrm{i}}$ ratio, $y_{\infty}$ is the asymptotic value of the $N / N_{\mathrm{i}}$ ratio, $\sigma$ is the cross section in $16 \mathrm{u} / \mathrm{eV}, D$ is the dose in $\mathrm{eV} / 16 \mathrm{u}$, and $Y_{0}$ is the extrapolated value of the $N / N_{\mathrm{i}}$ ratio for $D=0$. This extrapolated value is different from one because of the variation in the band strength of the considered species after irradiation. This variation is due to lattice damage and amorphisation and is almost complete at very low doses, i.e., before the first irradiation step. This assumption is supported by the goodness of the fit obtained. The column density rate (versus fluence) depends on destruction (in the bulk) and sputtering (at the surface). These two processes have a different dependence on the fluence (see e.g. Eq. (4) in Pilling et al. 2010), and their relative contribution depends strongly on the thickness of the sample. In our case, for the thickness used, sputtering is negligible. The formation of a new species is described by the exponential curve

$y=y_{\infty}\left(1-\mathrm{e}^{-\sigma D}\right)$,

where the same symbolism as in Eq. (3) has been used. In the following, the asymptotic value $y_{\infty}$ for water represents the fraction of $\mathrm{H}_{2} \mathrm{O}$ molecules remaining with respect to the initial $\mathrm{H}_{2} \mathrm{O}$ amount. For C-bearing species, it represents the amount remaining (or formed) relative to the amount of the initial C-bearing species. In the literature, $G$ values are often used to describe the formation and destruction of molecules. The $G$ values are defined as the number of molecules produced (destroyed) by an absorbed energy of $100 \mathrm{eV}$. The $G$ values depend on the irradiation fluence, thus initial yields are usually reported. However, $G$ values can be misleading for astrophysical applications. Laboratory experiments show that new species formed after ion irradiation (and UV photolysis) follow an (almost) linear trend at the beginning of irradiation and then flatten out reaching an equilibrium value. If irradiation proceeds further, new species are destroyed. Thus, if $G$ values are used to estimate the abundance of species produced after irradiation at high fluence, a very large abundance is obtained because $G$ values do not take into account the real trend of new species. We think that the cross-section and asymptotic value are more appropriate to describe the experimental results. 


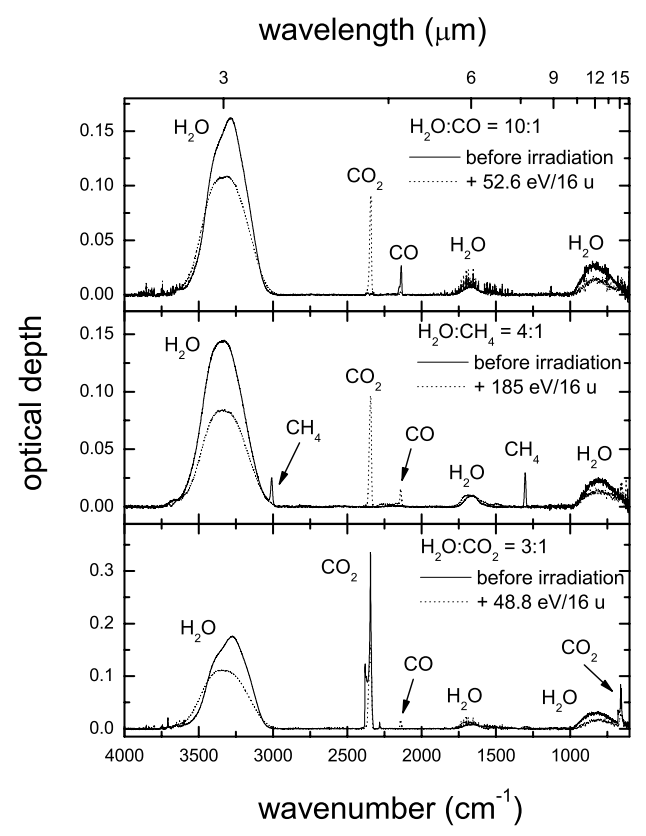

Fig. 1. IR transmittance spectra (in optical depth scale) of the mixtures studied in this work before and after irradiation at $12 \mathrm{~K}$ with $30 \mathrm{keV}$ $\mathrm{He}^{+}$.

Table 3. Peak position of the bands detected in the IR spectra of $\mathrm{H}_{2} \mathrm{O}: \mathrm{CO}=10: 1$ ice mixture at $12 \mathrm{~K}$ and $40 \mathrm{~K}$ before and after irradiation.

\begin{tabular}{|c|c|c|}
\hline \multicolumn{2}{|c|}{ Wavenumber $\left(\mathrm{cm}^{-1}\right)$} & \multirow[t]{2}{*}{ Molecule } \\
\hline $12 \mathrm{~K}$ & $40 \mathrm{~K}$ & \\
\hline 3285 & 3300 & $\mathrm{H}_{2} \mathrm{O}$ \\
\hline $2342^{*}$ & $2341^{*}$ & $\mathrm{CO}_{2}{ }^{*}$ \\
\hline 2137 & 2136 & $\mathrm{CO}$ \\
\hline 1660 & 1678 & $\mathrm{H}_{2} \mathrm{O}$ \\
\hline 820 & 824 & $\mathrm{H}_{2} \mathrm{O}$ \\
\hline $651^{*}$ & $650^{*}$ & $\mathrm{CO}_{2}{ }^{*}$ \\
\hline
\end{tabular}

Notes. ${ }^{(*)}$ Detected after irradiation.

\section{Results}

\subsection{Irradiation of $\mathrm{H}_{2} \mathrm{O}: \mathrm{CO}=10: 1$ mixture at $12 \mathrm{~K}$ and $40 \mathrm{~K}$}

In the IR transmittance spectra of a thin film of a $\mathrm{H}_{2} \mathrm{O}: \mathrm{CO}=10: 1$ ice mixture before irradiation at $12 \mathrm{~K}$ (Fig. 1 - top panel) and $40 \mathrm{~K}$, the most intense absorption bands observed at about 3300 , 1660 , and $820 \mathrm{~cm}^{-1}$ are due to solid water ice, while the band at about $2136 \mathrm{~cm}^{-1}$ is due to $\mathrm{CO}$ ice.

After irradiation with $30 \mathrm{keV} \mathrm{He}{ }^{+}$, in both samples, the intensity of these bands decreases and two new bands, amenable to $\mathrm{CO}_{2}$, are detected at 2342 and $650 \mathrm{~cm}^{-1}$ (see e.g., Moore et al. 1991). The peak position and identification of the bands detected in the samples at $12 \mathrm{~K}$ and $40 \mathrm{~K}$ before and after irradiation are listed in Table 3.

The values of the normalized column density of $\mathrm{H}_{2} \mathrm{O}, \mathrm{CO}$, and $\mathrm{CO}_{2}$ during irradiation, in the samples at both temperatures are plotted in Fig. 2. Column density values after irradiation are normalized to the initial column density values in order to compare the results relative to ice samples with slightly different initial thickness.

Water column densities at $12 \mathrm{~K}$ and $40 \mathrm{~K}$ decrease slowly and only in the first steps of irradiation. At around $30 \mathrm{eV} / 16 \mathrm{u}$, the water column density is $80-90 \%$ of its initial value, and appears to be unaffected by the temperature. These trends are

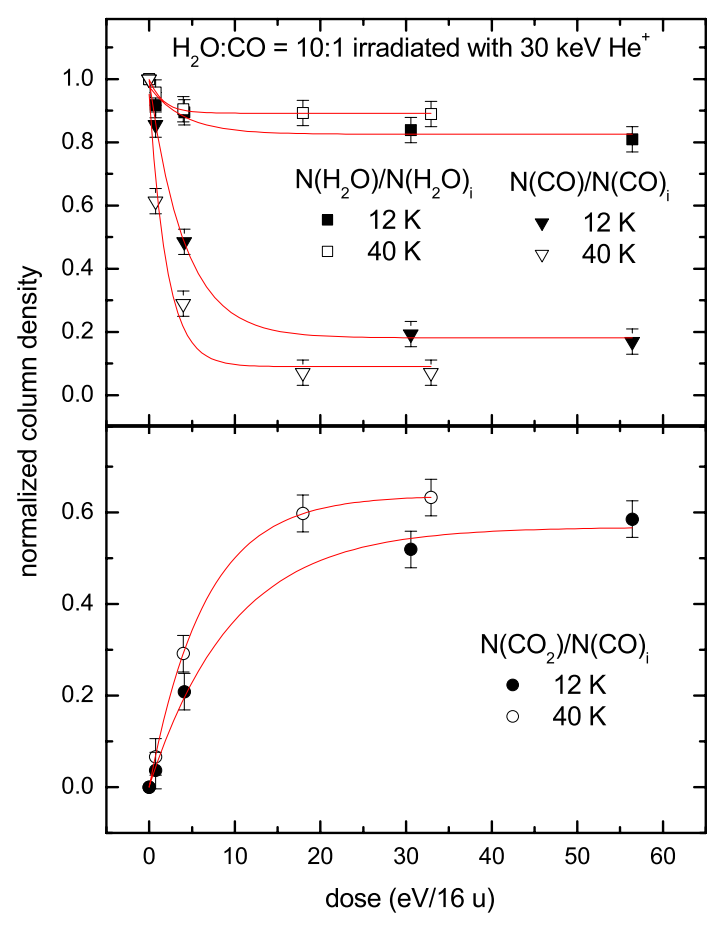

Fig. 2. Trend of the normalized column density of $\mathrm{H}_{2} \mathrm{O}, \mathrm{CO}$, and $\mathrm{CO}_{2}$

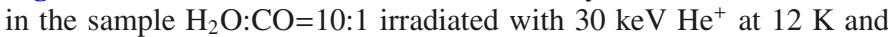
$40 \mathrm{~K}$, and their fit.

fitted by using Eq. (3) with the values of the parameters listed in Table 4.

We irradiated thin films of pure water ice at temperatures lower than $80 \mathrm{~K}$ and found that water has a very low destruction yield. Most of the dissociated molecules react to reform water and the water column density becomes about $95 \%$ of its initial value (Gomis et al. 2004). The destruction include both molecules sputtered away from the target and molecules processed to form $\mathrm{H}_{2} \mathrm{O}_{2}$, which is identifiable from the band at about $2850 \mathrm{~cm}^{-1}$. In the present experiments, we found a slightly higher destruction yield and we conclude that the presence of other species in the mixture (such as $\mathrm{CO}$ ) supports the formation of new molecules providing an alternative pathway to the reaction that reforms the water. This increases the destruction yield of water at temperatures lower than its sublimation temperature (about $160 \mathrm{~K}$ ). In particular, in the case of the $\mathrm{H}_{2} \mathrm{O}$ : $\mathrm{CO}$ mixture irradiated at $12 \mathrm{~K}$, the amount of $\mathrm{CO}_{2}$ formed is about $60 \%$ of the original $\mathrm{CO}$. After irradiation of pure $\mathrm{CO}$ (Ioppolo et al. 2009), the amount of $\mathrm{CO}_{2}$ formed is about $10 \%$ of the original $\mathrm{CO}$. By comparing these results, it is evident that $\mathrm{H}_{2} \mathrm{O}$ plays a relevant role in the formation of $\mathrm{CO}_{2}$. We estimated that the decrease in $\mathrm{H}_{2} \mathrm{O}$ column density is compatible with the increase in $\mathrm{CO}_{2}$ column density.

The CO column density, at the end of the experiment at $12 \mathrm{~K}$ is reduced to $20 \%$ of its initial value, while by the end of irradiation performed at $40 \mathrm{~K}$ it has become $10 \%$. In both experiments, $60 \%$ of $\mathrm{CO}$ was oxygenated to form $\mathrm{CO}_{2}$, while the remainder was sputtered, thermally desorbed, or used to form minor species not detected in our spectra and a carbon-rich residue. The data of CO column densities are fitted by using Eq. (3) with values listed in Table 4. The trends of the $\mathrm{CO}_{2}$ formation at the two temperatures are very similar and the $\mathrm{CO}_{2}$ normalized column density reaches, at the end of irradiation, the value of $60 \%$ with respect to the initial $\mathrm{CO}$, in both samples. To fit these data, Eq. (4) was used with the values listed in Table 4. Hence, the 
M. Garozzo et al.: The influence of temperature on the synthesis of new molecules

Table 4. Best-fit parameters following the fitting of the experimental data related to the samples $\mathrm{H}_{2} \mathrm{O}: \mathrm{CO}=10: 1$ at $12 \mathrm{~K}$ and $40 \mathrm{~K}$ with Eqs. (3) and (4).

\begin{tabular}{ccccccc}
\hline \hline & \multicolumn{2}{c}{$\left(Y_{0}-y_{\infty}\right)$} & \multicolumn{2}{c}{$\sigma(16 \mathrm{u} / \mathrm{eV})$} & \multicolumn{2}{c}{$y_{\infty}$} \\
& $12 \mathrm{~K}$ & $40 \mathrm{~K}$ & $12 \mathrm{~K}$ & $40 \mathrm{~K}$ & $12 \mathrm{~K}$ & $40 \mathrm{~K}$ \\
\hline $\mathrm{H}_{2} \mathrm{O}$ & $0.15 \pm 0.04$ & $0.11 \pm 0.01$ & $0.51 \pm 0.37$ & $0.61 \pm 0.08$ & $0.83 \pm 0.02$ & $0.89 \pm 0.01$ \\
$\mathrm{CO}$ & $0.81 \pm 0.01$ & $0.86 \pm 0.10$ & $0.24 \pm 0.01$ & $0.55 \pm 0.19$ & $0.18 \pm 0.01$ & $0.09 \pm 0.06$ \\
$\mathrm{CO}_{2}$ & & & $0.10 \pm 0.02$ & $0.15 \pm 0.02$ & $0.57 \pm 0.03$ & $0.64 \pm 0.03$ \\
\hline
\end{tabular}

Table 5. Peak position of the bands detected in the IR spectra of $\mathrm{H}_{2} \mathrm{O}: \mathrm{CH}_{4}=4: 1$ ice mixture as deposited at $12 \mathrm{~K}$ and $40 \mathrm{~K}$ and after irradiation.

\begin{tabular}{|c|c|c|}
\hline \multicolumn{2}{|c|}{ Wavenumber $\left(\mathrm{cm}^{-1}\right)$} & \multirow[t]{2}{*}{ Molecule } \\
\hline $12 \mathrm{~K}$ & $40 \mathrm{~K}$ & \\
\hline 3300 & 3291 & $\mathrm{H}_{2} \mathrm{O}$ \\
\hline 3010 & 3009 & $\mathrm{CH}_{4}$ \\
\hline 2975 & $2976^{*}$ & $\mathrm{C}_{2} \mathrm{H}_{6}{ }^{*}$ \\
\hline 2341 & $2341^{*}$ & $\mathrm{CO}_{2}{ }^{*}$ \\
\hline 2137 & $2136^{*}$ & $\mathrm{CO}^{*}$ \\
\hline 1680 & 1663 & $\mathrm{H}_{2}{ }^{*} \mathrm{O}$ \\
\hline 1500 & $1497^{*}$ & $\mathrm{H}_{2} \mathrm{CO}^{*}$ \\
\hline 1301 & 1301 & $\mathrm{CH}_{4}$ \\
\hline 1017 & $1017^{*}$ & $\mathrm{CH}_{3} \mathrm{OH}$ \\
\hline 807 & 806 & $\mathrm{H}_{2} \mathrm{O}$ \\
\hline
\end{tabular}

Notes. ${ }^{(*)}$ Detected after irradiation.

higher cross-section for disappearance of $\mathrm{CO}$ at $40 \mathrm{~K}$ is probably due to its desorption and not to a more efficient dissociation of this molecule. The role of temperature in these samples became evident when we considered that the ratio $\mathrm{H}_{2} \mathrm{O}: \mathrm{CO}$ increased from 10:1 before irradiation to 40:1 at the end of irradiation at $12 \mathrm{~K}$ and to $140: 1$ at the end of irradiation at $40 \mathrm{~K}$.

\subsection{Irradiation of $\mathrm{H}_{2} \mathrm{O}: \mathrm{CH}_{4}=4: 1$ mixture at $12 \mathrm{~K}$ and $40 \mathrm{~K}$}

Figure 1 (middle panel) shows the IR spectra of a thin film of $\mathrm{H}_{2} \mathrm{O}: \mathrm{CH}_{4}=4: 1$ ice mixture deposited at $12 \mathrm{~K}$ together with the IR spectrum of the same sample after irradiation with $30 \mathrm{keV} \mathrm{He}^{+}$. These spectra are similar to those of the sample prepared and irradiated at $40 \mathrm{~K}$. The irradiation of these mixtures led to the production of several new molecules, mainly $\mathrm{CO}_{2}$ but also $\mathrm{CO}$, ethane $\left(\mathrm{C}_{2} \mathrm{H}_{6}\right)$, formaldehyde $\left(\mathrm{H}_{2} \mathrm{CO}\right)$, and methanol $\left(\mathrm{CH}_{3} \mathrm{OH}\right)$ (see e.g., Baratta et al. 2003). Peak positions and the identification of the bands detected before and after irradiation can be found in Table 5. All the bands clearly present in the spectra are included in the table. From other experiments (e.g. Baratta et al. 2003), we know that other species (such as $\mathrm{C}_{3} \mathrm{H}_{8}$ and $\mathrm{C}_{2} \mathrm{H}_{4}$ ) are formed after the irradiation of $\mathrm{H}_{2} \mathrm{O}: \mathrm{CH}_{4}$ mixtures. However, because of the lower thickness of the samples in the present experiments the bands corresponding to these species are not evident in the spectra.

The normalized column densities of $\mathrm{H}_{2} \mathrm{O}$ and $\mathrm{CH}_{4}$ at $12 \mathrm{~K}$ and $40 \mathrm{~K}$ are plotted as a function of the dose in Fig. 3. To fit these data, Eq. (3) was used with the parameter values listed in Table 6.

In these mixtures, the water column density decreases slowly with irradiation and at $12 \mathrm{~K}$ has not reached the asymptotic value even at the highest investigated dose. At a dose of $140 \mathrm{eV} / 16 \mathrm{u}$, the value of the water column density is around $70 \%$ of its initial value at both considered temperatures. We note that the normalized water column density is higher than one at the beginning of irradiation at $12 \mathrm{~K}$. This is not a real growth but an effect of

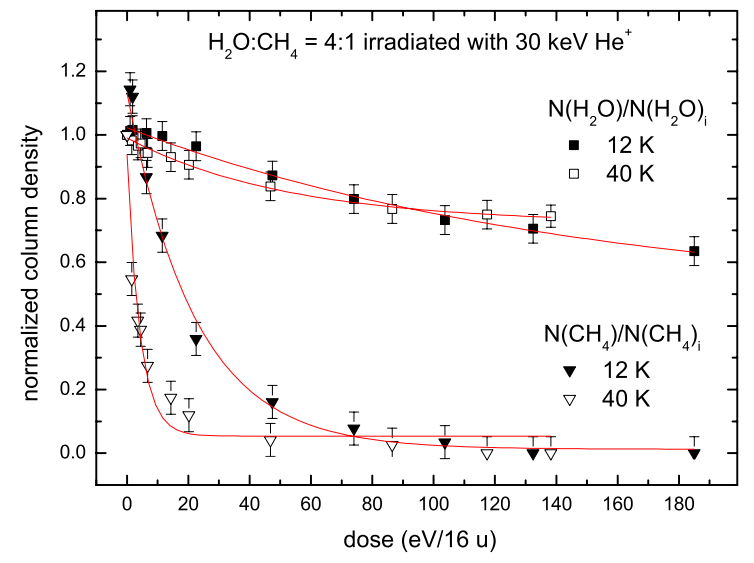

Fig. 3. Trend of the column density of the parent molecules in the mixture $\mathrm{H}_{2} \mathrm{O}: \mathrm{CH}_{4}=4: 1$ during irradiation with $30 \mathrm{keV} \mathrm{He}^{+}$at $12 \mathrm{~K}$ and $40 \mathrm{~K}$ and their fit.

the variation in the band strength of the $3 \mu \mathrm{m}$ band of water ice during irradiation as studied by Leto \& Baratta (2003).

At $12 \mathrm{~K}$, the $\mathrm{CH}_{4}$ normalized column density value has a very prompt drop off at the beginning of irradiation and is less than $20 \%$ of its initial value at around $40 \mathrm{eV} / 16 \mathrm{u}$ dose. At $40 \mathrm{~K}$, this process appears to be very rapid as the ratio $\sigma(40 \mathrm{~K}) / \sigma(12 \mathrm{~K})=5$ (see Table 6) clearly indicates. Furthermore, at the end of both experiments, $\mathrm{CH}_{4}$ is undetectable at both temperatures. In the first steps of irradiation at $12 \mathrm{~K}$, the normalized column density of $\mathrm{CH}_{4}$ is higher than one. As in the case of water ice previously described, this is due to the variation in the band strength value as discussed in Leto \& Baratta (2003) and Loeffler et al. (2005).

The ratio $\mathrm{H}_{2} \mathrm{O}: \mathrm{CH}_{4}$ changes significantly after irradiation. The initial ratio $4: 1$ has increased to $90: 1$ by the end of irradiation at $12 \mathrm{~K}$ and to more than 105:1 by the end of irradiation at $40 \mathrm{~K}$.

The trend of the $\mathrm{CO}_{2}$ formation as a function of dose at $12 \mathrm{~K}$ and $40 \mathrm{~K}$ is shown in Fig. 4. The formation of $\mathrm{CO}_{2}$ molecules is more effective at low temperature as becomes evident at irradiation doses higher than $40 \mathrm{eV} / 16 \mathrm{u}$. At the highest investigated dose, the maximum ratio of the produced $\mathrm{CO}_{2}$ to the initial $\mathrm{CH}_{4}$ is $40 \%$.

Owing to the change in the $\mathrm{CO}_{2}$ production rate at a "threshold dose $D_{0}$ " of about $20 \mathrm{eV} / 16 \mathrm{u}$, the trend of $\mathrm{CO}_{2}$ column density at $12 \mathrm{~K}$ is fitted with two exponential curves. In detail,

$y=y_{1}\left(1-\mathrm{e}^{-\sigma_{1} D}\right) \quad$ when $D \leq D_{0}$

$y=y_{1}\left(1-\mathrm{e}^{-\sigma_{1} D}\right)+y_{2}\left[1-\mathrm{e}^{-\sigma_{2}\left(D-D_{0}\right)}\right] \quad$ when $\quad D>D_{0}$

where $y_{1}$ and $y_{2}$ are the asymptotic values, $\sigma_{1}$ and $\sigma_{2}$ are the cross-sections, and $D$ is the dose. The values of these parameters are listed in Table 7 . The production rate of $\mathrm{CO}_{2}$ at $40 \mathrm{~K}$ could 
Table 6. Best-fit parameters following the fitting of the experimental data related to the samples $\mathrm{H}_{2} \mathrm{O}: \mathrm{CH}_{4}=4: 1$ at $12 \mathrm{~K}$ and $40 \mathrm{~K}$ with Eq. (3).

\begin{tabular}{ccccccc}
\hline \hline \multicolumn{2}{c}{$\left(Y_{0}-y_{\infty}\right)$} & \multicolumn{2}{c}{$\sigma(16 \mathrm{u} / \mathrm{eV})$} & \multicolumn{2}{c}{$y_{\infty}$} \\
& $12 \mathrm{~K}$ & $40 \mathrm{~K}$ & $12 \mathrm{~K}$ & $40 \mathrm{~K}$ & $12 \mathrm{~K}$ & $40 \mathrm{~K}$ \\
\hline $\mathrm{H}_{2} \mathrm{O}$ & $0.55 \pm 0.07$ & $0.27 \pm 0.01$ & $(7.04 \pm 1.49) \times 10^{-3}$ & $(1.86 \pm 0.20) \times 10^{-2}$ & $0.47 \pm 0.07$ & $0.72 \pm 0.01$ \\
$\mathrm{CH}_{4}$ & $1.12 \pm 0.05$ & $0.88 \pm 0.07$ & $(4.58 \pm 0.62) \times 10^{-2}$ & $0.24 \pm 0.04$ & $0.01 \pm 0.03$ & $0.05 \pm 0.04$ \\
\hline
\end{tabular}

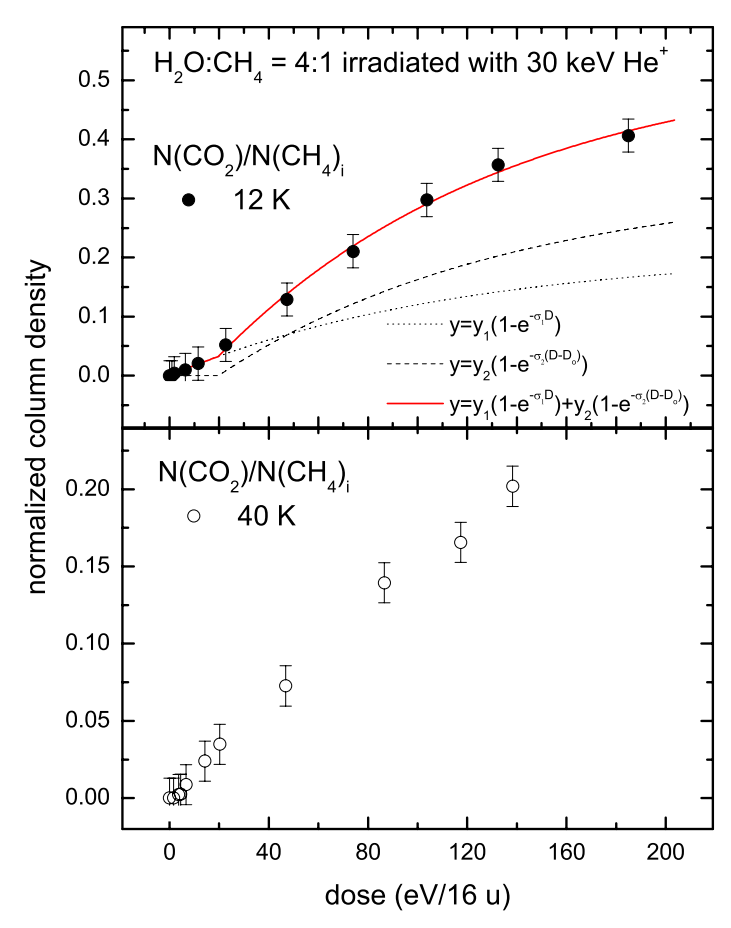

Fig. 4. Trend of the normalized column density of $\mathrm{CO}_{2}$ synthesized in the mixture $\mathrm{H}_{2} \mathrm{O}: \mathrm{CH}_{4}=4: 1$ at various steps of irradiation and at two different temperatures. For $12 \mathrm{~K}$, the fit is also shown.

be fitted with a straight line, given by the relation $y=y_{1} \times \sigma_{1} \times D$, so only the product $y_{1} \times \sigma_{1}$ could be evaluated.

The formation of $\mathrm{CO}$ molecules as a function of the dose is shown in Fig. 5. The CO formation is quite effective at $12 \mathrm{~K}$, reaching $25 \%$ of initial $\mathrm{CH}_{4}$, while at $40 \mathrm{~K}$ the $\mathrm{CO}$ abundance remains less than $10 \%$ of initial $\mathrm{CH}_{4}$ during the experiment, hence in this case, temperature also plays a significant role.

As for $\mathrm{CO}_{2}$ at $12 \mathrm{~K}$, the trend of $\mathrm{CO}$ was fitted with the two exponential curves described by Eqs. (5) and (6) with the parameter values listed in Table 7. In the case of the curve that fits the CO trend at $40 \mathrm{~K}$ for $D>D_{0}$, a straight line is produced by the fitting procedures. Developing the exponential in a Mac Laurin series and stopping it at the first order, the equation is approximated by the relationship $y=\sigma_{2} \times y_{2} \times\left(D-D_{0}\right)$, which is the equation of a straight line. Thus, it is impossible to calculate separately $\sigma_{2}$ and $y_{2}$ since the fitting procedure depends only on their product.

After irradiation, the column density of water and methane decreases, while the column density of newly formed species, such as $\mathrm{CO}$ and $\mathrm{CO}_{2}$, increases. We note that at low doses the trend of $\mathrm{CO}$ and $\mathrm{CO}_{2}$ production differs from that at higher doses. Furthermore, at low doses, the main molecules formed are hydrocarbons (Baratta et al. 2002), whose column density decreases at higher doses when the $\mathrm{CO}$ and $\mathrm{CO}_{2}$ column densities increase. First and second generation molecules therefore exist. The presence of newly formed solid CO in the mixture is consistent with $\mathrm{CO}_{2}$ synthesis, because reactions with $\mathrm{CO}$ as a

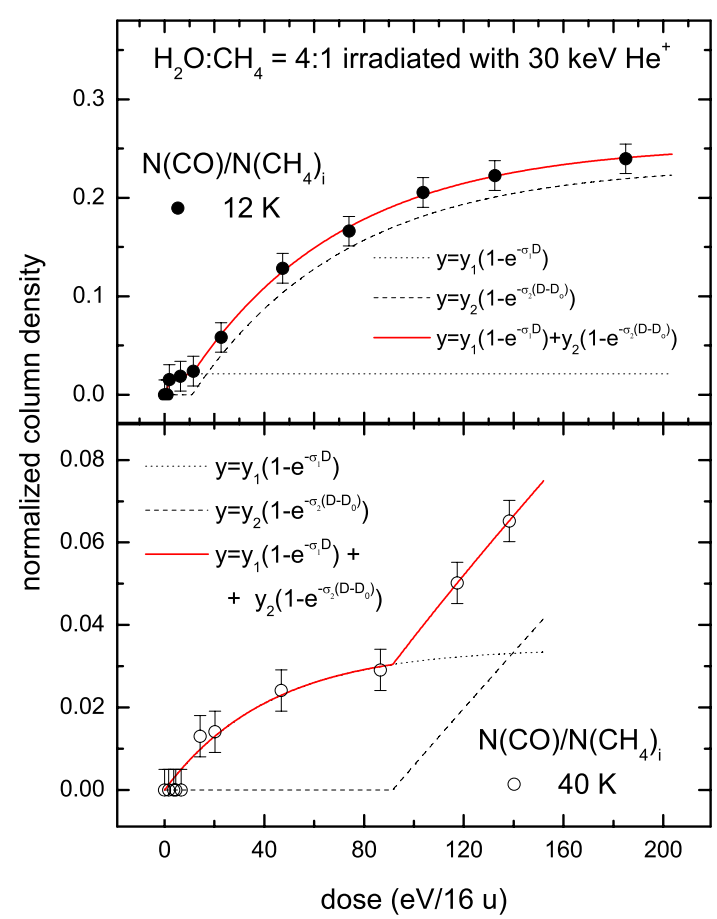

Fig. 5. Trend of the normalized column density of $\mathrm{CO}$ formed in the mixture $\mathrm{H}_{2} \mathrm{O}: \mathrm{CH}_{4}=4: 1$ at various steps of irradiation and at two different temperatures together with the fit.

precursor, such as $\mathrm{CO}+\mathrm{OH}$, are significant. In addition, $\mathrm{CO}_{2}$ could be formed by reactions that do not have $\mathrm{CO}$ as a precursor. In particular, Ferini et al. (2004) and Palumbo et al. (2004) demonstrated that a refractory organic residue is formed after irradiation of $\mathrm{CH}_{4}$-bearing icy mixtures. We consider this residue to be a $\mathrm{C}$ reservoir that contributes to the formation of $\mathrm{CO}$ and $\mathrm{CO}_{2}$ at high doses. We performed several blank experiments (see e.g. Mennella et al. 2004; and Strazzulla et al. 2003) irradiating pure water ice, which show that $\mathrm{CO}$ and $\mathrm{CO}_{2}$ contamination is negligible.

\subsection{Irradiation of $\mathrm{H}_{2} \mathrm{O}: \mathrm{CO}_{2}=3: 1$ mixture at $12 \mathrm{~K}$ and $60 \mathrm{~K}$}

The last experiments described in this paper concern the irradiation of two icy mixtures $\mathrm{H}_{2} \mathrm{O}: \mathrm{CO}_{2}=3: 1$ at $12 \mathrm{~K}$ and $60 \mathrm{~K}$. The spectrum of the sample at $12 \mathrm{~K}$ before and after irradiation is shown in Fig. 1 (bottom panel). The main difference between these two spectra is the decrease in the intensity of the band areas of $\mathrm{H}_{2} \mathrm{O}$ and $\mathrm{CO}_{2}$ and the appearance of a new band due to $\mathrm{CO}$ at $2141 \mathrm{~cm}^{-1}$. After irradiation, $\mathrm{CO}$ is not the only molecular species that we detected: we also detect carbon trioxide $\left(\mathrm{CO}_{3}\right)$, ozone $\left(\mathrm{O}_{3}\right)$, hydrogen peroxide $\left(\mathrm{H}_{2} \mathrm{O}_{2}\right)$, and carbonic acid $\left(\mathrm{H}_{2} \mathrm{CO}_{3}\right)$ (see e.g., Strazzulla et al. 2005). The peak positions and identification of the molecular species detected in the mixtures at $12 \mathrm{~K}$ and $60 \mathrm{~K}$ before and after irradiation are listed in Table 8. 
M. Garozzo et al.: The influence of temperature on the synthesis of new molecules

Table 7. Best-fit parameters following the fitting of the experimental data related to $\mathrm{CO}$ and $\mathrm{CO}_{2}$ formed after irradiation of the sample $\mathrm{H}_{2} \mathrm{O}: \mathrm{CH}_{4}=4: 1$ at $12 \mathrm{~K}$ and $40 \mathrm{~K}$ with Eqs. (5) and (6).

\begin{tabular}{lccccc}
\hline \hline & $\begin{array}{c}D_{0} \\
(\mathrm{eV} / 16 \mathrm{u})\end{array}$ & $y_{1}$ & $\begin{array}{c}\sigma_{1} \\
(16 \mathrm{u} / \mathrm{eV})\end{array}$ & $y_{2}$ & $\begin{array}{c}\sigma_{2} \\
(16 \mathrm{u} / \mathrm{eV})\end{array}$ \\
\hline $\mathrm{CO}_{2}(12 \mathrm{~K})$ & $19 \pm 3$ & $0.21 \pm 0.01$ & $(8.7 \pm 2.0) \times 10^{-3}$ & $0.33 \pm 0.01$ & $(8.8 \pm 3.8) \times 10^{-3}$ \\
$\mathrm{CO}(12 \mathrm{~K})$ & $11 \pm 3$ & $(2.1 \pm 0.8) \times 10^{-2}$ & $0.37 \pm 0.31$ & $0.23 \pm 0.01$ & $(1.6 \pm 0.2) \times 10^{-2}$ \\
$\mathrm{CO}(40 \mathrm{~K})$ & $91 \pm 5$ & $(3.4 \pm 2.0) \times 10^{-2}$ & $(2.3 \pm 1.0) \times 10^{-2}$ & & \\
\hline
\end{tabular}

Table 8. Peak position of the bands detected in the IR spectra of $\mathrm{H}_{2} \mathrm{O}: \mathrm{CO}_{2}=3: 1$ ice mixture at $12 \mathrm{~K}$ and $60 \mathrm{~K}$ before and after irradiation.

\begin{tabular}{|c|c|c|}
\hline \multicolumn{2}{|c|}{ Wavenumber $\left(\mathrm{cm}^{-1}\right)$} & \multirow[t]{2}{*}{ Molecule } \\
\hline $12 \mathrm{~K}$ & $60 \mathrm{~K}$ & \\
\hline 3708 & 3707 & $\mathrm{CO}_{2}$ \\
\hline 3589 & 3599 & $\mathrm{CO}_{2}$ \\
\hline 3274 & 3280 & $\mathrm{H}_{2} \mathrm{O}$ \\
\hline $2850^{*}$ & $2856^{*}$ & $\mathrm{H}_{2} \mathrm{O}_{2}{ }^{*}$ \\
\hline 2344 & 2344 & $\mathrm{CO}_{2}$ \\
\hline 2282 & 2281 & ${ }^{13} \mathrm{CO}_{2}$ \\
\hline $2141^{*}$ & $2139^{*}$ & $\mathrm{CO}^{*}$ \\
\hline $2045^{*}$ & $2045^{*}$ & $\mathrm{CO}_{3}{ }^{*}$ \\
\hline 1664 & 1669 & $\mathrm{H}_{2} \mathrm{O}$ \\
\hline $1500^{*}$ & $1497^{*}$ & $\mathrm{H}_{2} \mathrm{CO}_{3}{ }^{*}$ \\
\hline $1309^{*}$ & $1301^{*}$ & $\mathrm{H}_{2} \mathrm{CO}_{3}{ }^{*}$ \\
\hline $1038^{*}$ & $1040^{*}$ & $\mathrm{O}_{3}{ }^{*}$ \\
\hline 836 & 836 & $\mathrm{H}_{2} \mathrm{O}$ \\
\hline 660 & 657 & $\mathrm{CO}_{2}$ \\
\hline
\end{tabular}

Notes. ${ }^{(*)}$ Detected after irradiation.

In Fig. 6, the trends of the normalized column density of $\mathrm{H}_{2} \mathrm{O}, \mathrm{CO}_{2}$, and $\mathrm{CO}$ at $12 \mathrm{~K}$ and $60 \mathrm{~K}$ are plotted as a function of the dose. Equation (3) is used to fit the $\mathrm{H}_{2} \mathrm{O}$ and $\mathrm{CO}_{2}$ data, while Eq. (4) is used to fit the CO data. The values of the parameters used in these equations are listed in Table 9.

In these experiments, water exhibits a different behavior with temperature; at $12 \mathrm{~K}$, its column density suddenly decreases during the first step of irradiation to $85 \%$, a value close to the asymptotic value. At $60 \mathrm{~K}$, the water column density decreases with a more uniform behavior during irradiation, reaching $85 \%$ of its initial value at high doses. The $\mathrm{CO}_{2}$ column density is unaffected by temperature, and it decreases almost in the same way at both temperatures reaching a value around $50 \%$ of the initial $\mathrm{CO}_{2}$ value at high doses. The ratio $\mathrm{H}_{2} \mathrm{O}: \mathrm{CO}_{2}$ increased from the initial 3:1 ratio before irradiation to a final $4: 1$ at $12 \mathrm{~K}$ and 5:1 at $60 \mathrm{~K}$. These results show how the temperature does not play a significant role in this case. The CO column density also shows a similar behavior at both temperatures. It increases rapidly and reaches saturation at a dose higher than $15 \mathrm{eV} / 16 \mathrm{u}$. However, there is a small difference in the amount of $\mathrm{CO}$ produced at different temperatures: $20 \%$ of initial $\mathrm{CO}_{2}$ at $12 \mathrm{~K}$ and $12 \%$ at $60 \mathrm{~K}$. The minor amount of $\mathrm{CO}$ at $60 \mathrm{~K}$ is most likely due to its desorption.

\section{Discussion}

We have performed a set of experiments designed to the study of the formation of $\mathrm{CO}_{2}$ and $\mathrm{CO}$ and the decrease in the original species after the ion irradiation of various icy mixtures at different temperatures. In detail, $\mathrm{H}_{2} \mathrm{O}: \mathrm{CO}=10: 1$ and $\mathrm{H}_{2} \mathrm{O}: \mathrm{CH}_{4}=4: 1$ mixtures were irradiated at $12 \mathrm{~K}$ and $40 \mathrm{~K}$. We found that the decrease in $\mathrm{CO}$ and $\mathrm{CH}_{4}$ is faster at $40 \mathrm{~K}$, which is a

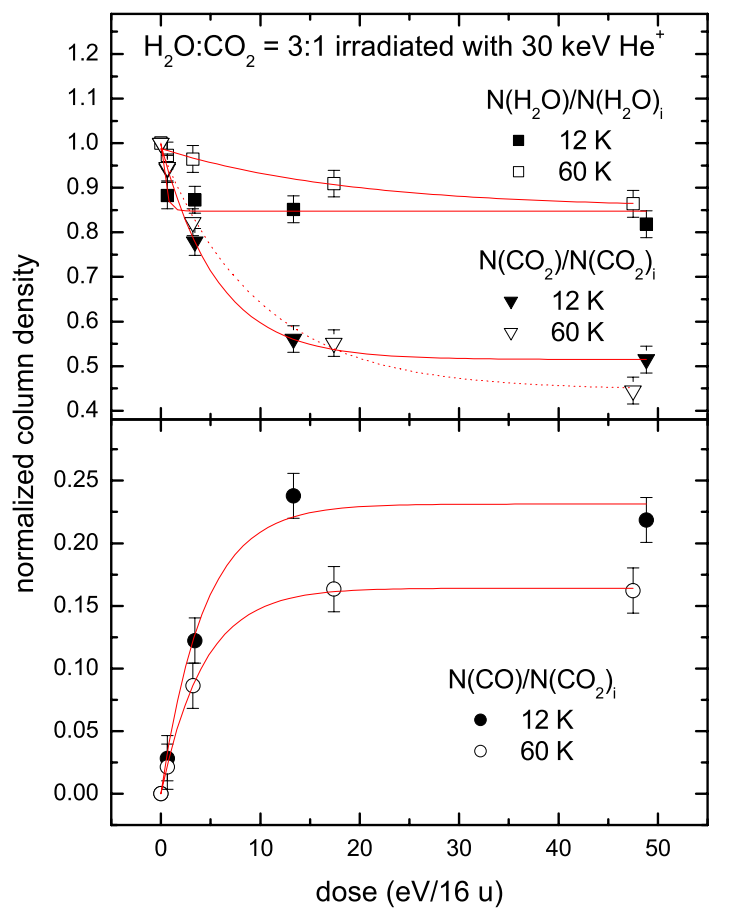

Fig. 6. Trend of $\mathrm{H}_{2} \mathrm{O}, \mathrm{CO}_{2}$, and $\mathrm{CO}$ column density at various steps of irradiation of the sample $\mathrm{H}_{2} \mathrm{O}: \mathrm{CO}_{2}=3: 1$ at two different temperatures together with their fit.

temperature higher than their sublimation temperature $(\sim 30 \mathrm{~K})$, rather than at $12 \mathrm{~K}$. The difference is higher for the $\mathrm{CH}_{4}$ molecules. The $\mathrm{H}_{2} \mathrm{O}: \mathrm{CO}_{2}=3: 1$ mixture was irradiated at $12 \mathrm{~K}$ and $60 \mathrm{~K}$, which are values lower than the sublimation temperature of $\mathrm{CO}_{2}(\sim 90 \mathrm{~K})$. The trend of $\mathrm{CO}_{2}$ destruction at both temperatures is the same within the error of the measurement.

In the mixtures with $\mathrm{CO}$ and $\mathrm{CO}_{2}$, the water column density decreases when subjected to low doses of irradiation and immediately reaches an asymptotic value in the range of $80-90 \%$ of its initial value. For mixtures containing $\mathrm{CH}_{4}$, the water column density decreases during the whole irradiation process without reaching an asymptotic value even at high doses.

We irradiated thin films of pure water ice at temperatures lower than $80 \mathrm{~K}$ and found that water has a very low destruction yield and that at the end of the experiments, the water column density was about $95 \%$ of its initial value (Gomis et al. 2004). The destruction include both molecules sputtered away from the target and molecules processed to form $\mathrm{H}_{2} \mathrm{O}_{2}$, which is identified from the band at about $2850 \mathrm{~cm}^{-1}$. In the present experiments, we found a slightly higher destruction yield and conclude that the presence of other species in the mixture (such as $\mathrm{CO}$, $\mathrm{CO}_{2}$, and $\mathrm{CH}_{4}$ ) promotes the formation of new molecules and increases the destruction yield of water at temperatures lower than its sublimation temperature (about $160 \mathrm{~K}$ ). In the case of $\mathrm{H}_{2} \mathrm{O}: \mathrm{CH}_{4}$ mixtures, a C-rich refractory residue is formed after 
Table 9. Best-fit parameters following the fitting of the experimental data related to the samples $\mathrm{H}_{2} \mathrm{O}: \mathrm{CO}_{2}=3: 1$ at $12 \mathrm{~K}$ and $60 \mathrm{~K}$ with Eqs. (3) and (4).

\begin{tabular}{lcccccc}
\hline \hline & \multicolumn{2}{c}{$\left(Y_{0}-y_{\infty}\right)$} & \multicolumn{2}{c}{$\sigma(16 \mathrm{u} / \mathrm{eV})$} & \multicolumn{2}{c}{$y_{\infty}$} \\
& $12 \mathrm{~K}$ & $60 \mathrm{~K}$ & $12 \mathrm{~K}$ & $60 \mathrm{~K}$ & $12 \mathrm{~K}$ & $60 \mathrm{~K}$ \\
\hline $\mathrm{H}_{2} \mathrm{O}$ & $0.15 \pm 0.03$ & $0.13 \pm 0.02$ & $3.60 \pm 2.15$ & $0.07 \pm 0.03$ & $0.85 \pm 0.02$ & $0.85 \pm 0.02$ \\
$\mathrm{CO}_{2}$ & $0.48 \pm 0.01$ & $0.54 \pm 0.02$ & $0.18 \pm 0.01$ & $0.10 \pm 0.02$ & $0.51 \pm 0.01$ & $0.45 \pm 0.02$ \\
$\mathrm{CO}$ & & & $0.23 \pm 0.04$ & $0.23 \pm 0.01$ & $0.23 \pm 0.01$ & $0.16 \pm 0.01$ \\
\hline
\end{tabular}

irradiation (e.g. Ferini et al. 2004; Palumbo et al. 2004). This residue is a source of carbon and explains the formation of $\mathrm{CO}$ and $\mathrm{CO}_{2}$ and the destruction of water at high doses when almost no $\mathrm{CH}_{4}$ is left in the sample.

The formation of $\mathrm{CO}$ and $\mathrm{CO}_{2}$ is directly related to the type of irradiated mixtures. The formation of $\mathrm{CO}_{2}$ after irradiation of $\mathrm{H}_{2} \mathrm{O}: \mathrm{CO}$ mixtures is slightly temperature dependent, but strongly depends on the temperature when $\mathrm{H}_{2} \mathrm{O}: \mathrm{CH}_{4}$ mixtures are irradiated. Moreover, the formation of $\mathrm{CO}$ after the irradiation of the $\mathrm{H}_{2} \mathrm{O}: \mathrm{CH}_{4}$ and $\mathrm{H}_{2} \mathrm{O}: \mathrm{CO}_{2}$ mixtures is also temperature dependent and more likely at lower temperatures $(12 \mathrm{~K})$. The production cross-section of $\mathrm{CO}_{2}$ is higher in the mixture $\mathrm{H}_{2} \mathrm{O}$ : $\mathrm{CO}$, where the value of the $\mathrm{CO}_{2}$ column density reaches saturation after $\sim 30 \mathrm{eV} / 16 \mathrm{u}$ at both temperatures, while in the mixture $\mathrm{H}_{2} \mathrm{O}: \mathrm{CH}_{4}$ the saturation of $\mathrm{CO}_{2}$ column density is not reached in any case, even at the higher investigated doses. Similarly the $\mathrm{CO}$ column density reaches the saturation value after irradiation of the mixture $\mathrm{H}_{2} \mathrm{O}: \mathrm{CO}_{2}$, while in the mixture $\mathrm{H}_{2} \mathrm{O}: \mathrm{CH}_{4}$ the $\mathrm{CO}$ molecules are synthesized even at doses higher than $140 \mathrm{eV} / 16 \mathrm{u}$. However, in this mixture at $12 \mathrm{~K}$ and $40 \mathrm{~K}$, at doses higher than $80 \mathrm{eV} / 16 \mathrm{u}, \mathrm{CH}_{4}$ is almost totally destroyed, and the production of $\mathrm{CO}$ and $\mathrm{CO}_{2}$ can proceed only because of the presence of a $\mathrm{C}$-rich residue. The formation of an organic residue after the ion irradiation of icy mixtures containing $\mathrm{C}$-, $\mathrm{H}$-, and O-bearing species is supported by several laboratory investigations (e.g., Ferini et al. 2004).

Our experimental results show that the fate of the volatile species, such as $\mathrm{CO}$ and $\mathrm{CH}_{4}$, is strongly dependent on the temperature. The $\mathrm{CO}_{2}$ production is not strongly affected by temperature in $\mathrm{H}_{2} \mathrm{O}: \mathrm{CO}$ mixtures, but in the case of $\mathrm{H}_{2} \mathrm{O}: \mathrm{CH}_{4}$ mixtures the production of $\mathrm{CO}$ and $\mathrm{CO}_{2}$ is less efficient at higher temperatures. Therefore, although an increase in temperature increases the diffusion rates of the reactants that produce $\mathrm{CO}_{2}$, it does not enhance the efficiency of its production. Thermal desorption of the $\mathrm{CO}$ and $\mathrm{CO}_{2}$ precursor species tends to inhibit the formation process of the final products.

\section{Astrophysical applications}

In dense molecular clouds $\left(>10^{4} n_{\mathrm{H}} \mathrm{cm}^{-3}\right)$, gas phase species condense on grains forming icy mantles. Some species (such as $\mathrm{CO}$ ) directly freeze out from the gas phase, while other molecules (such as $\mathrm{H}_{2} \mathrm{O}$ ) are formed after grain surface reactions. Icy mantles have been observed in quiescent regions along the line of sight toward field stars (e.g., Chiar et al. 1994, 1995; Whittet et al. 1998) and along the line of sight toward YSOs (Tielens et al. 1991; Gerakines et al. 1999; Gibb et al. 2004; Pontoppidan et al. 2008). A detailed study of the absorption profile of observed bands indicates that annealing occurs in icy mantles around YSOs (Gerakines et al. 1999; Dartois \& d'Hendecourt 2001; Pontoppidan et al. 2008). Icy mantles are continuously exposed to energetic processes such as low-energy cosmic-ray irradiation and UV photolysis and these alter both the chemical and the lattice structure of the target material with the formation of molecular species. It has been estimated that the proton flux, following the approximation of monoenergetic $1 \mathrm{MeV}$ protons, has a value of 1.8 protons $\mathrm{cm}^{-2} \mathrm{~s}^{-1}$ in diffuse quiescent regions and 1 proton $\mathrm{cm}^{-2} \mathrm{~s}^{-1}$ in dense quiescent regions (Mennella et al. 2003). The UV flux under diffuse medium conditions has been estimated as $8 \times 10^{7}$ photons $\mathrm{cm}^{-2} \mathrm{~s}^{-1}$ (Mathis et al. 1983). In dense regions, the internal UV flux due to cosmic-ray induced fluorescence of molecular hydrogen ranges from $1.4 \times 10^{3}$ to $4.8 \times 10^{3}$ photons $\mathrm{cm}^{-2} \mathrm{~s}^{-1}$ (Prasad \& Tarafdar 1983; Mennella et al. 2003). Considering the amount of energy released by ions and photons passing through an ice mantle, the effects of UV photons would dominate in diffuse regions while the effects of ions and UV photons are comparable in dense regions (Moore, 1999). Greenberg (1982) estimated that the lifetime of a dense cloud is in the interval $3 \times 10^{7}-5 \times 10^{8}$ years. Assuming a density of $n=10^{4} n_{\mathrm{H}} \mathrm{cm}^{-3}, 10^{9} / n \sim 10^{5}$ years are needed for gas to condense onto grains (Tielens \& Allamandola 1987). Thus, icy grain mantles are irradiated for a time that ranges from $10^{5}$ years (the grain mantles sublime immediately after the formation) to $5 \times 10^{8}$ years (the icy grain mantles survive for all the cloud lifetime). The specific energy loss (stopping power) of $1 \mathrm{MeV}$ protons into a typical grain containing heavy atoms $(\mathrm{C}, \mathrm{N}, \mathrm{O}, \mathrm{Si})$ is $\sim 5 \times 10^{-15} \mathrm{eV} \mathrm{cm}^{2}$ atom $^{-1}$. The energy deposited on a grain (dose), given by the product of the stopping power, the flux, and the mantle lifetime is around 0.015-75 eV/atom $(\mathrm{C}, \mathrm{N}, \mathrm{O}, \mathrm{Si})$. In star-forming regions, the flux of ions due to stellar flares must also be considered. This flux was estimated by Strazzulla et al. (1983) to be 200 protons $\mathrm{cm}^{-2} \mathrm{~s}^{-1}$, so the energy deposited onto a grain in $10^{6}$ years (a YSO lifetime) is around $30 \mathrm{eV} /$ atom $(\mathrm{C}, \mathrm{N}, \mathrm{O}, \mathrm{Si}$ ). Mixtures studied in this work were irradiated with a dose in the range 0.6-185 eV/16 u, which is comparable with the higher values of doses absorbed by icy mantles.

Our experimental results show that the formation of molecular species does not depend on the temperature while the temperature of the sample is lower than the sublimation temperature of the investigated species. On the basis of our results, we expect that the amount of $\mathrm{CO}_{2}$ formed during the YSO stage is comparable to the amount formed in quiescent regions. The dose suffered by icy mantles in quiescent regions is indeed comparable to the dose suffered during the YSO stage.

Ruffle \& Herbst (2001a,b) published models of coupled gasphase and grain surface chemistry. In these models, the effects of grain mantle photodissociation were investigated by considering as photon sources the background interstellar and cosmic-rayinduced radiation fields. They found that, in general, an increase in temperature leads to a significant increase in surface $\mathrm{CO}_{2}$ production because the diffusion rates of the reactants that produce $\mathrm{CO}_{2}$ become much higher and competitive reactions involving $\mathrm{H}$ atoms become less important as $\mathrm{H}$ desorbs more quickly. If we assume that the effects of photons and fast ions are the same, the experimental results presented here do not support their finding. However, this conclusion needs more experimental work to be confirmed. The comparison between experimental results 
and models is not straightforward. Furthermore, Ruffle \& Herbst $(2001 \mathrm{a}, \mathrm{b})$ consider the effects of photons that, in principle, could behave differently from fast ions (see e.g. Baratta et al. 2002).

Finally we note that the observed abundance of $\mathrm{CH}_{4}$ is about $1-4 \%$ with respect to water towards high-mass YSOs (Gibb et al. 2004; Boogert et al. 1997) and about 2-8\% towards low-mass YSOs (Öberg et al. 2008). In particular, the model by Ruffle \& Herbst (2001a), which takes into account photochemistry, predicts a value of $\mathrm{CH}_{4}$ higher than $10 \%$ with respect to water ice, which is higher than the observed values. On the basis of our experimental results, we suggest that cosmic-ion and UV irradiation could contribute to the destruction and consequently to the low abundances of $\mathrm{CH}_{4}$ in icy grain mantles.

Acknowledgements. We thank F. Spinella for his help in the laboratory. This research has been supported by Italian Space Agency contract No. I/015/07/0 (Studi di Esplorazione del Sistema Solare) and by the European Community's Seventh Framework Programme (FP7/2007-2013 under grant agreement No. 238258).

\section{References}

Allamandola, L. J., Sandford, S. A., \& Valero, G. J. 1988, Icarus, 76, 225 Baratta, G. A., \& Palumbo, M. E. 1998, J. Opt. Soc. Am. A, 15, 3076 Baratta, G. A., Palumbo, M. E., \& Strazzulla, G. 2000, A\&A, 357, 1045 Baratta, G. A., Leto, G., \& Palumbo, M.E. 2002 A\&A, 384, 343

Baratta, G. A., Domingo, M., Ferini, G., et al. 2003, NIMB, 209, 283

Boogert, A. C. A., Schutte, W. A., Helmich, F. P., Tielens, A. G. G. M., \& Wooden, D. H. 1997, A\&A, 317, 929

Boogert, A. C. A., Pontoppidan, K. M., Lahuis, F., et al. 2004, ApJS, 154, 359

Boonman, A. M. S., van Dishoeck, E. F., Lahuis, F., \& Doty, S. D. 2003, A\&A, 399,1063

Chiar, J. E., Adamson, A. J., Kerr, T. H., \& Whittet, D. C. B. 1994, ApJ, 426, 240

Chiar, J. E., Adamson, A. J., Kerr, T. H., \& Whittet, D. C. B. 1995, ApJ, 455, 234

Dartois, E., \& d'Hendecourt, L. 2001, A\&A, 365, 144

Dulieu, F., Amiaud, L., Congiu, E., et al. 2010, A\&A, 512, A30

d'Hendecourt, L. B., Allamandola, L. J., Grim, R. J. A., \& Greenberg, J. M. 1986, A\&A, 158, 119

Ehrenfreund, P., Boogert, A. C. A., Gerakines, P. A., Tielens, A. G. G. M., \& van Dishoeck, E. F. 1997, A\&A, 328, 649

Ferini, G., Baratta, G. A., \& Palumbo, M. E. 2004, A\&A, 414, 757

Fraser, H. J., \& van Dishoeck, E. F. 2004, Adv. Space Res., 33, 14

Fuchs, G. W., Cuppen, H. M., Ioppolo, S., et al. 2009, A\&A, 505, 629

Fulvio, D., Sivaraman B., Baratta, G.A., et al. 2009, Spectrochimica Acta A, 72, 1007

Garozzo, M., Fulvio, D., Kanuchova, Z., Palumbo, M. E., \& Strazzulla, G. 2010, A\&A, 509, A67

Gerakines, P. A., Schutte, W. A., \& Ehrenfreund, P. 1996, A\&A, 312, 289

Gerakines, P. A.,Whittet, D. C. B., Ehrenfreund, P., et al. 1999, ApJ, 522, 357

Gibb, E. L., Whittet, D. C. B., Boogert, A. C. A., \& Tielens, A. G. G. M. 2004 , ApJS, 151, 35

Gomis, O., Leto, G., \& Strazzulla, G. 2004, A\&A, 420, 405
Greenberg, M. 1982, in Comets, ed. L.L. Wilkening (Tucson: The University of Arizona Press), 131

Hiraoka, K., Miyagoshi, T., Takayama, T., Yamamoto, K., \& Kihara, Y. 1998, ApJ, 498, 710

Ioppolo, S., Cuppen, H. M., Romanzin, C., van Dishoeck, E. F., \& Linnartz, H. 2008, ApJ, 686, 1474

Ioppolo, S., Palumbo, M. E., Baratta G. A., \& Mennella, V. 2009, A\&A, 493, 1017

Jenniskens, P., Baratta, G. A., Kouchi, A., et al. 1993, A\&A, 273, 583

Jiang, G. J., Person, W. B., \& Brown, K. G. 1975, J. Chem. Phys., 62, 1201

Leto, G., \& Baratta, G. A. 2003, A\&A, 397, 7

Loeffler, M. J., Baratta, G. A., Palumbo, M. E., Strazzulla, G., \& Baragiola, R. A. 2005, A\&A, 435, 587

Mathis, J. S., Mezger, P. G., \& Panagia, N. 1983, A\&A, 128, 212

Mennella, V., Baratta, G. A., Esposito, A., Ferini, G., \& Pendleton, Y. J. 2003, ApJ, 587, 727

Mennella, V., Palumbo, M. E., \& Baratta, G. A. 2004, ApJ, 615, 1073

Mennella, V., Baratta, G. A., Palumbo, M. E., \& Bergin, E. A. 2006, ApJ, 643, 923

Modica, P., \& Palumbo, M. E. 2010, A\&A, 519, A22

Moore, M. H. 1999, in Solid Interstellar Matter: the ISO Revolution, ed. L. d'Hendecourt, C. Joblin, \& A. Jones (New York: Springer-Verlag), 199

Moore, M. H., Khanna, R., \& Donn, B. 1991, J. Geophys. Res., 96, 17541

Mulas, G., Baratta, G. A., Palumbo, M. E., \& Strazzulla, G. 1998, A\&A, 333, 1025

Nummelin, A., Whittet, D. C. B., Gibb, E. L., Gerakines, P. A., \& Chiar, J. E. 2001, ApJ, 558, 185

Öberg, K., Boogert, A. C. A., Pontoppidan, K. M., et al. 2008, ApJ, 678, 1032

Palumbo, M. E., \& Strazzulla, G. 1993, A\&A, 269, 568

Palumbo, M. E., Baratta, G. A., Brucato, J. R., et al. 1998, A\&A, 334, 247

Palumbo, M. E., Ferini, G., \& Baratta, G. A. 2004, Adv. Sp. Res., 33, 49

Palumbo, M. E., Baratta, G. A., Collings, M. P., \& McCoustra, M. R. S. 2006, Phys. Chem. Chem. Phys., 8, 279

Pilling, S., Seperuelo Duarte, E., da Silveira, E. F., et al. 2010, A\&A, 509, A87

Pontoppidan, K. M., Boogert, A. C. A., Fraser, H. J., et al. 2008, ApJ, 678, 1031

Prasad, S. S., \& Tarafdar, S. P. 1983, ApJ, 267, 603

Quirico, E., \& Schmitt, B. 1997, Icarus, 127, 354

Ruffle, D. P., \& Herbst, E. 2001a, MNRAS, 322, 770

Ruffle, D. P., \& Herbst, E. 2001b, MNRAS, 324, 1054

Satorre, M. A., Palumbo, M. E., \& Strazzulla, G. 2000, Ap\&SS, 274, 643

Stantcheva, T., \& Herbst, E. 2004, A\&A, 423, 241

Strazzulla, G., Calcagno, L., \& Foti, G. 1983, MNRAS, 204, 59

Strazzulla, G., Baratta G. A., \& Palumbo M. E. 2001, Spectrochim. Acta, 57, 825

Strazzulla, G., Leto, G., Gomis, O., \& Satorre, M. A. 2003, Icarus, 164, 163

Strazzulla, G., Leto, G., Spinella, F., \& Gomis, O. 2005, AsBio, 5, 612

Tielens, A. G. G. M., \& Allamandola, L. J. 1987, ASSL, 134, 397

Tielens, A. G. G. M., \& Hagen, W. 1982, A\&A, 114, 245

Tielens, A. G. G. M., Tokunaga, A. T., Geballe, T. R., \& Baas, F. 1991, ApJ, 381, 181

van Dishoeck, E. F., Helmich, F. P., de Graauw, T., et al. 1996, A\&A, 315, L349

Watanabe, N., \& Kouchi, A. 2002, ApJ, 571, L173

Whittet, D. C. B., Gerakines, P. A., Tielens, A. G. G. M., et al. 1998, ApJ, 498, L159

Whittet, D. C. B., Shenoy, S. S., Bergin, E. A., et al. 2007, ApJ, 655, 332

Yamada, H., \& Person, W. B. 1964, J. Chem. Phys., 41, 2478

Ziegler J. F., Biersack, J. P., \& Ziegler M. D., 2008, The stopping and range of ions in solids (New York: Pergamon Press), see also http: //www . srim.org 